\title{
Wastewater-based SARS-CoV-2 environmental monitoring for Piedmont, Italy
}

Angelo Robotto ${ }^{1}$, David Lembo ${ }^{3}$, Paola Quaglino ${ }^{1}$, Enrico Brizio ${ }^{1}$, Denis Polato ${ }^{1}$, Andrea Civra ${ }^{3}$, Jessica Cusato ${ }^{4}$, Giovanni Di Perri

${ }^{1}$ Environmental Protection Agency of Piedmont (Arpa Piemonte), Via Pio VII 9, 10135 Torino, Italy

2 Infectious Diseases Unit, Department of Medical Sciences, University of Torino, Amedeo di Savoia Hospital, Torino, Italy

${ }^{3}$ Università degli Studi di Torino, Dept. of Clinical and Biological Sciences, Regione Gonzole 10, 10043 Orbassano, Torino, Italy

${ }^{4}$ Laboratory of Clinical Pharmacology and Pharmacogenetics, Department of Medical Sciences, University of Torino, Amedeo di Savoia Hospital, Torino, Italy

Corresponding Author:

Enrico Brizio,

Environmental Protection Agency of Piedmont (Arpa Piemonte),

Via Pio VII 9,

10135 Torino, Italy

Tel.: +39-0171329266; Fax: +39-0171329201

E-mail: e.brizio@arpa.piemonte.it 


\section{ABSTRACT}

The experience gained over the last hundred years clearly indicates that two groups of viruses represent the main risk for the development of highly transmissible epidemics and pandemics in the human species: influenza viruses and coronaviruses (CoV). Although the search for viruses with pandemic potential in the environment may have an important predictive and monitoring role, it is still based on empirical methodologies, mostly translated from the clinic and not fully validated for environmental matrices.

As far as the SARS-CoV-2 pandemic, currently underway, is concerned, environmental monitoring activities aiming at checking the presence of SARS-CoV-2 in wastewater can be extremely useful to predict and control the diffusion of the disease.

For this reason, the present study aims to evaluate the SARS-CoV-2 diffusion by means of a wastewaterbased environmental monitoring developed in Piedmont, N-W Italy, during the pandemic second and third waves.

Sampling strategies, sampling points, sample pre-treatments and analytical methods have been developed and validated to give representative and reliable results. The outcomes highlighted by the present paper demonstrate a strong correlation between SARS-CoV-2 concentration in untreated wastewater and epidemic evolution in the considered areas as well as a predictive potential that could provide decisionmakers with indications for establishing effective policies to mitigate the effects of the ongoing pandemic and to prepare response plans for future pandemics that could certainly arise in the decades to come.

Moreover, the study highlights the potential of wastewater treatment plants to degrade the genetic material referable to SARS-CoV-2 as well.

In conclusion, the preliminary data reported in the present paper, although they need to be complemented by further studies considering other geographical regions as well, are very promising.

Keywords:

SARS-CoV-2

Wastewater treatment plant

Environmental Virology

Monitoring and Surveillance

E gene

\section{Funding sources}

This research did not receive any specific grant from funding agencies in the public, commercial, or not-for-profit sectors. 


\section{Introduction}

The current Covid-19 pandemic, by the SARS-CoV-2 coronavirus, represents an unprecedented worldwide public health emergency. SARS-CoV-2 is a highly contagious respiratory virus, whose death toll overcome 3.4 million people by May 2021.

Although some residual uncertainties still surround the mode of spread of SARS-CoV-2, the airborne transmission as well as contagion from droplets fall on inanimate surfaces are today recognized, while the fecal-oral route is also being considered (Marquez et Domingo, 2021).

Regardless the actual epidemiological relevance of the fecal-oral route in SARS-CoV-2 transmission, it has been repeatedly proven that (Medema et al., 2020; Wu et al., 2020; Ahmed et al., 2020a) SARS-CoV-2 genetic material is consistently detectable in untreated wastewater, generally inactivated. Several studies reported the detection of SARS-CoV-2 RNA in untreated wastewater with concentrations in the range $10^{2}$ $10^{5}$ copies per litre with a maximum of over $10^{6}$ copies per litre (Kitajima et al., 2020). Based on the fact that SARS-CoV-2 viral loads in COVID-19 patients faeces range between $10^{5}$ and $10^{8}$ copies per gram of faeces (a value comparable to those of many enteric viruses), wastewater sampling and surveillance (Wastewater-Based Epidemiology or WBE) could actually serve as a complementary method for evaluating the spread of infection in selected areas, especially where resources for clinical diagnosis are limited and tracking systems are unavailable or suboptimal.

WBE is a relatively young research field and consists of wastewater analysis to identify the presence of biological or chemical products for public health monitoring purposes. Before the outbreak of the Covid-19 pandemic, WBE was used to detect and measure the presence of pharmaceutical or industrial waste, to search for viruses (poliovirus, enterovirus, hepatitis) and the potential emergence of antibiotic-resistant bacteria, and to monitor drug use.

Although epidemiology based on the analysis of wastewaters cannot, as obvious, identify SARS-CoV-2 infected people, it has noticeable advantages in the management of the pandemic evolution, roughly described as follows.

Firstly, the surveillance of wastewaters can highlight the onset of new epidemic waves in the catchment area served by the sampled wastewater treatment plant in a measureable advance. SARS-CoV-2 RNA can in fact be detected in human faeces up to a week before the start of symptoms related to the disease (Furukawa et al., Tindal et al., 2020), thus anticipating the results of diagnostic tests and hospitalizations due to Covid-19. Moreover, a wastewater sample can provide data on the average SARS-CoV-2 infection rate of thousands of people. Aggregated data can be particularly useful for areas where it is not possible to establish massive screening campaigns with diagnostic tests. Furthermore, continuous monitoring of wastewater, coupled with a wide spread of sampling points throughout the territory, identify new 
outbreaks and, from January 2021, might contribute to evaluate the influence and efficacy of the current vaccination campaign on the containment of the disease.

Wastewater surveillance could monitor the presence of SARS-CoV-2 within large communities, such as big cities, but also smaller groups, such as university, public offices, prisons.

Finally, wastewater surveillance could help improving the development of knowledge in relation to the diffusion of new SARS-CoV-2 variants according to the indications of national and international health authorities.

As a matter of facts, based on the COMMISSION RECOMMENDATION (EU) 2021/472 of 17 March 2021, EU Member States are strongly encouraged to put in place as soon as possible and no later than 1st October 2021 a national wastewater surveillance system targeted at data collection of SARS-CoV-2 and its variants in wastewaters.

Nevertheless, it should be considered that the results reported by literature could be strongly influenced by the sample pre-treatment technique, that is necessary to concentrate the virus; indeed, while SARS-CoV-2 is an enveloped virus (i.e. its viral particle is endowed with a highly labile, double-layered phospholipid bilayer surrounding the protein viral nucleocapsid), many current techniques (electropositive or electronegative membranes, ultrafiltration, polyethylene glycol (PEG) precipitation, ultracentrifugation, skimmed-milk flocculation) have been developed mainly to concentrate non-enveloped enteric viruses such as norovirus, enterovirus, adenovirus, and hepatitis A virus. In particular, the virus concentration recovery efficiencies of SARS-CoV-2, not often known at the moment, may be quite different from those of nonenveloped enteric viruses: such a difference could determine errors as big as one order of magnitude in the estimated concentration of SARS-CoV-2 in untreated wastewater (Ahmed et al., 2020b). Moreover, data regarding the sampling strategy (grab or composite) or even reverse transcription-quantitative polymerase chain reaction (RT-qPCR) assay limit of detection (LoD) are often not declared or not available.

For these reasons, aim of this study was to perform the wastewater sampling, along with sample pretreatment, conservation and analysis, focusing on Piedmont region.

Piedmont is a region placed in North Western Italy, with more than 4.3 million of inhabitants. In Piedmont there are 171 wastewater treatment plants (WWTP) over 2000 population equivalents (PE), treating 93\% of the overall regional pollutant load, and more than 2600 settlements under 2000 PE (Regione Piemonte, 2020).

The length of the regional sewer network is $21,665 \mathrm{~km} \mathrm{(5} \mathrm{m} \mathrm{per} \mathrm{inhabitants),} \mathrm{the} \mathrm{wastewater} \mathrm{volume}$ treated by WWTPs is around 314 million $\mathrm{m}^{3} / \mathrm{y}$.

The Environmental Protection Agency of Piedmont (Arpa Piemonte) is in charge of controlling the discharges of urban and industrial wastewater treatment plants of the Region by means of instantaneous, 3 
hours and 24 hours weighted average sampling, according to laws in force in Italy. Moreover, the Agency carries out discharge control also by sampling wastewater upstream of WWTP, as well as the monitoring of surface and underground water bodies quality. During the spring 2020, Arpa Piemonte invited the regional Integrated Water Service Managers to operate the disinfection of the wastewater in order to minimize the infectivity of viral particles that may have been found in sewers.

The sampling and analysis of untreated wastewater, surface water that may be subject to untreated discharges and purified discharges represent the key to understand the interactions between SARS-CoV-2 and the environment, aspects that fully fall within the functions of the environmental agencies.

Given that only a fraction of infected individuals are tested, but SARS-CoV-2 is present in the stool of infected people, as well as in their urine and respiratory secretions (nasal lavages, tissues), taking into account that the sewerage network collects excreta from all individuals, including SARS-CoV-2 presymptomatic and asymptomatic ones, wastewater systematic collection and monitoring better represents the true SARS-CoV-2 circulation within the population of the WWTP served area.

The ability to systematically collect wastewater samples on a large number of plants over 2000 population equivalents should be coupled with the precise knowledge of sewer networks in order to better identify the onset of an outbreak of the disease. Figure 1 reports an example of sewer network for the city of Torino and surrounding towns.

\section{Materials and methods}

\subsection{Wastewater sampling plan}

Concerning wastewater samplings aiming at SARS-CoV-2 surveillance, some essential aspects must be addressed:

1. sampling points should be chosen in order to be representative of the population distributed on the territory;

2. sampling strategy should be decided considering that grab samples could give only a partial information of wastewater composition. On the contrary, composite samples, in particular flow-composite, can be more representative, as highlighted by previous studies on different human markers in wastewater (Ort et al., 2010);

3. the frequency of wastewater collection should be as high as possible (bimonthly, weekly or even higher);

4. the volume of sampled wastewater should be in the range $50-200 \mathrm{~mL}$; 
5. transport temperature of samples should be $4^{\circ} \mathrm{C}$. Medema et al. (2020) demonstrated that SARS-CoV-2 RNA is stable in wastewater when stored at $5^{\circ} \mathrm{C}$.

Considering that Arpa Piemonte also manages a virological laboratory, given its prerogatives in terms of control and monitoring of the environmental media, starting from the month of September, on a bimonthly basis, samples of wastewater entering the 13 WWTPs reported by Table 1 and Figure 2 were taken. All considered plants have tertiary treatment.

In the present report, we focused the attention on 3 WWTPs:

1) Castiglione Torinese ( $\mathrm{N}-\mathrm{W}$ of the region), collecting wastewater from 44 towns (among them, Torino) and almost 1.5 million people,

2) Asti (S-E of the region), with a treatment capacity of 95,000 population equivalents

3) Govone (S-W of the region), with a treatment capacity of 240,000 population equivalents, collecting wastewater from 27 towns (Alba among them).

Figure 2 reports the position of the plants.

Other regional WWTP inlets (5 plants around Alessandria) have been sampled with different frequencies following a control criterion inspired by greater territorial capillarity. The corresponding results will not be considered in the present paper.

To ensure maximum significance to the environmental monitoring undertaken, instant samples and 24 hours flow-composite samples were carried out. Similarly, the WWTP have been chosen in order to cover all 8 Piedmont provinces according to criteria aimed at guaranteeing the representativeness of the results that can be obtained and the maximization of the underlying population. The wastewater treated by the selected WWTPs accounts for much more than a half of the population living in Piedmont.

All samples were stored at a temperature of $-20^{\circ} \mathrm{C}$. Up to now, the total number of wastewater samples is greater than 400 .

\subsection{Wastewater sample pre-treatment and analysis}

In December 2020, the experimental tests were completed for the development and validation of a method for the detection of SARS-Cov2 in wastewater. The analytical protocol developed includes a phase of concentration/extraction of genetic material and a subsequent amplification phase by RT-Realtime PCR (three specific targets for the SARS-CoV-2 virus and two targets used as controls of the analytical process).

Total Nucleic Acid (TNA) extraction is performed using $40 \mathrm{ml}$ of wastewater collected either from a 500 $\mathrm{mL}$ or $1 \mathrm{~L}$ collection bottles from a wastewater system at specific points. Both grab samples and 24- 
hours composite samples have been collected. The samples have been frozen at $-20^{\circ} \mathrm{C}$ and transferred to the laboratory.

At the time of analysis, the samples have been completely thawed using a $37^{\circ} \mathrm{C}$ water bath. $40 \mathrm{~mL}$ of water have been collected in a Class II biosafety cabinet. TNA extraction has been performed using the Wastewater Large Volume Total Nucleic Acid Capture Kit AX9550 (Promega Corporation, USA). Briefly, the extraction consists of 2 steps: in the first one the TNA is captured on a GFA/silica column and then eluted in $1 \mathrm{ml}$; in the second step, the TNA is purified and concentrated in $40 \mu \mathrm{l}$.

The SARS-CoV-2 RT-qPCR detection KIT for Wastewater (Promega Corporation, USA) is used for the amplification phase. The detected regions are N1 and N2 (regions of the Nucleocapsid gene) and E (region of the Envelope gene).

The kit can also evaluate a series of very important analytical process controls to normalize obtained data and avoid the presence of false negatives:

- a set of primers and probe for the detection of an "internal process control" target (Pepper Mild Mottle Virus PMMoV, a RNA virus commonly found in faeces) that allows to monitor the entire analytical process (extraction phase, reverse transcription, absence of inhibitors); this kind of internal control is not influenced by seasonal fluctuations or social aspects (D.Aoust et al., 2020);

- an internal amplification control (IAC) that allows to check that there are no inhibitors during the amplification phase.

The PCR Master MIX, necessary for amplification to take place, is designed in order to avoid that different compounds (e.g. humic acids), normally present in wastewater samples, van act as PCR inhibitors.

PCR samples are analysed in duplicate for each of the targets (N1, N2 E, PMMoV, IAC).

The results are expressed with the CT values (Cycle Threshold) for each detected target. In case of absence of amplification (absence of the desired target) the result is reported as Ct> 40 . The theoretical LoD (I.C. at $95 \%)$ is 3 genomic copies per reaction.

The specificity of the RT-PCR kit has been further investigated using RNA from HCoV-OC43 (Human Coronavirus OC43) and from HCoV-229E (Human Coronavirus 229E). HCoV-OC43 belongs to the Betacoronavirus genus like SARS-CoV-2, whereas HCoV-229E belongs to the Alphacoronavirus genus; both are endemic in the human population. 


\section{Results}

Based on the preliminary tests carried out with a SARS CoV-2 RNA standard/reference material (LGC, UK), the recovery efficiency of the concentration/extraction/purification phase turned out to be around $50 \%$. These results would be pretty good if compared with recovery efficiencies reported by Ahmed et al. (2020b), who tested the efficiency of seven wastewater virus concentration methods (adsorptionextraction with three different pre-treatment options, centrifugal filter device methods with two different devices, polyethylene glycol (PEG 8000) precipitation, and ultracentrifugation) on murine hepatitis virus (MHV), finding mean recoveries ranging from 26.7 to $65.7 \%$.

Taking into account the recovery efficiency attributed to the virus concentration/extraction/purification phase, the overall analytical LoD for the applied protocol would be around 1,200 genetic copies per liter of raw wastewater, that is very close to the detection limit of $10^{3}$ copies/L estimated by Wurtzer et al. (2020).

The specificity of the applied RT-PCR kit for SARS-CoV-2 has been demonstrated: no amplification and no aspecific signals have been detected in any of the two samples containing HCoV-OC43 and HCoV-229E.

In all the analysed wastewater samples, the presence of the 3 different virus-specific target sequences $(E$, N1 and N2) was detected, indicating the presence of SARS-CoV-2 RNA in the samples undergoing analysis.

The data reported in Figures 3, 4 and 5 show that concentration in wastewater, expressed as CT values of SARS-CoV-2 E gene, anticipates the trend of disease. Here, the peak values, in all the reported cases well below CT 30, correspond to concentrations ranging from 400 to 600 SARS-CoV-2 genomic copies per mL of raw wastewater.

Figure 6 reports the CT values of the 3 different targets (N1, N2 and E genes) obtained for wastewater collected by WWTP placed in Novara, N-E part of the region, showing a good overall agreement.

\section{Discussion}

On the basis of the reported results, the first aspect to observe is that the peak values, corresponding to concentrations ranging from 400 to 600 SARS-CoV-2 genomic copies per $\mathrm{mL}$ of raw wastewater, perfectly fall within the range reported by Medema et al. (2020) regarding an EU-wide feasibility study based on tests developed in 52 WWTPs serving cities of 17 countries (the concentrations turned out to be 1-946 gene (N2) copies per $\mathrm{mL}$ ) .

Then, comparisons can be made with the Covid-19 reported number of active cases in the WWTP catchment area, showing a strong correlation between SARS-CoV-2 concentration in sewers and diagnostic 
tests results, perfectly in line with the indications of the literature studies. The same correlation could be found between SARS-CoV-2 concentration and incidence of new cases of Covid-19 in the catchment area.

The preliminary results obtained by our research group formed by the Environmental Protection Agency of Piedmont (Arpa Piemonte) and Università degli Studi di Torino clearly pointed out all potentiality of wastewater monitoring in order to provide authorities with helpful data to manage SARS-CoV-2 pandemic outbreaks.

The systematic application of the described monitoring approach to a large number of WWTPs over a vast territory, within the regional environmental monitoring plan carried out by Arpa Piemonte, could be the basis of a new dynamic knowledge of the spread mechanisms of the disease.

Given that the concentration trends do matter most, starting from the trends it is possible to refine the environmental monitoring going upstream from the initial sampling points, analysing the wastewater in the various branches of the network in search of the primary outbreak. As a matter of facts, wastewater samplings could be done also through sewer pumping stations or via manholes in the street (Weidhaas et al., 2020) or the sewer pipes leaving a single building or structure.

The analysis of wastewater concentration trends, associated with demographic, social and geographic statistics, could help identify a few key monitoring points at a regional level serving as an early warning network to monitor fluctuations of SARS-CoV-2 circulation in communities.

Moreover, the monitoring activities carried out in the last 8 months have pointed out that, even though the wastewater entering the WWTP could be strongly positive for SARS-CoV-2, genetic materials referable to the virus are not detectable in the discharged waters, after treatment. This statement has been tested both in Castiglione Torinese and Govone WWTP, confirming similar results reported by other studies (ISS, 2020).

As for wastewater treatments, the current purification practices are effective to degrade the virus, given the retention times combined with hostile environmental conditions (temperature, solar irradiation, high $\mathrm{pH}$ levels, indigenous microbial populations). The final disinfection optimizes the conditions for the complete removal of the virus before the purified water is reintroduced into the environment.

Concerning the quantification of SARS-CoV-2 prevalence in the population from wastewater surveillance, Medema et al. (2020) reported a comparison between theory and practice of quantitative relation between SARS-CoV-2 circulation in the population and SARS-CoV-2 RNA in wastewater.

Theory is based on the following simplified formula: 


$$
C_{\text {sewage }}=\frac{N \cdot F_{L} \cdot C_{\text {faeces }}}{Q}
$$

where $C_{\text {sewage }}$ is wastewater SARS-CoV-2 concentration, $N$ is is the number of people shedding, $F_{L}$ is the faecal load (g/person/day), $C_{\text {faeces }}$ is the concentration of RNA in the faeces of infected people and $Q$ is the total flow to sewer per day.

Based on literature reported by the cited author, SARS-CoV-2 concentration in the faeces can vary from $10^{2}$ to $10^{10}$ genetic copies per gram, according to time of infection (some studies report that pre-symptomatic time represents the peak of shedding), and person-to-person variability (not all stool samples from infected patients are positive for SARS-CoV-2 RNA). Medema reports that the large uncertainty observed in faeces SARS-CoV-2 concentration is interpreted as an erratic behaviour by some author (Walsh et al., 2020). After all, great variability of virus shedding potential is not unexpected as observed SARS-CoV-2 concentration ranges from $10^{2}$ to $10^{11}$ RNA copies/mL of mucus in swab samples in asymptomatic persons as well (Buonanno et al., 2020).

The uncertainty budget relating to the term $C_{\text {faeces }}$ is much higher than the other factors' ones of the reported formula, strongly influencing the overall uncertainty of the quantification approach. Medema reports the results of a Monte Carlo simulation where a concentration of 1,000 SARS-CoV-2 genomic copies per $\mathrm{mL}$ of sewage corresponds to a prevalence in the range $70-3,000$ infected persons per 100,000 inhabitants. Similar results were pointed out by Ahmed et al. (2020a) who report: <<given the uncertainty and variation in the input parameters, the model (Monte Carlo simulation) estimated a median range of 171 to 1,090 infected persons in the catchment>>.

Anyway, SARS-CoV-2 prevalence estimates based on wastewater surveillance are still generally highly uncertain, mostly because of the need of reliable and complete data on virus RNA shedding by asymptomatic and presymptomatic people. The development of epidemiological models and serological data could help future progress.

Consequently, wastewater surveillance benefit mostly relies on trend assessment, mainly when analysis and trends are produced by the same laboratory with the same method and approach. Medema concludes: $<$ When trends in individual case reporting and sewage numbers are consistent, added confidence is provided to public health authorities in their current course of action $\gg$. This is a totally shareable position. 


\section{Conclusions}

The current circulation of SARS-CoV-2 is characterized by successive major waves of diffusion whose magnitude was found to depend upon the degree of restrictions applied as well as on the transmissibility of novel variants and the vaccine coverage being now provided. Hospitals hosting COVID-19 patients had to arrange an unprecedented number of extra beds in order to face the sharp increase in severely ill patients requiring ventilation support. This led to a significant reduction of a series of conventional medical activities, whose actual public health consequences will need years to be fully measured. In such circumstances, the possibility to rely upon signals heralding the forthcoming rise of patients requiring hospital-based assistance would be of critical importance in order to fruitfully anticipate those measures enabling to increase the hospitals capacity. Although virtually neglected in this pandemic, the rise of SARSCoV-2 infection incidence in vulnerable age groups might actually anticipate by 7-10 days a proportional increase in hospitalization, and by an average of 14 days the subsequent rise in mortality. In this perspective, wastewater sampling with quantitation of SARS-CoV-2 appears not only to be much less cumbersome as compared to human data gathering, but also able to further anticipate the subsequent medical events.

The management of COVID-19 pandemic second and third wave requires the application of every available scientific evolution. Wastewater-based epidemiology could be of primary importance in the present phase, but standardization of analytical methods and environmental sampling processes could result still missing.

Within the described framework, since September 2020 a wastewater sampling plan has been applied regarding the main wastewater treatment plants of the region Piedmont, Italy. At the same time, Arpa Piemonte and Università degli Studi di Torino, developed an analytical method validated, adequate and immediately usable for the enduring wastewater monitoring activities.

After 8 months, the historical trends of SARS-CoV-2 concentration in untreated wastewater are at disposal for the entire duration of the second wave in 13 regional WWTPs serving most of the regional population.

The exploitation of the capabilities acquired by the Agency in the field of environmental virology, together with the consolidated environmental monitoring and control skills, represent an opportunity for efficient, useful and cost-effective actions against pandemic, at present and in the future.

The analytical results already available today on a regional scale clearly show a strong correlation between the concentration of the virus in wastewater and, as suggested by numerous scientific studies on the subject, the incidence and prevalence of the disease in the population. Moreover, in the context of the ongoing massive vaccination campaign this approach will contribute to answer the question of whether vaccines will reduce not only the incidence of the COVID-19 disease but also SARS-CoV-2 circulation among the population. 
The data obtainable with the described approach can therefore represent a valid support for subsequent processing and elaborations, including epidemiological ones, by Health Authorities, thus realizing the regulatory provisions aiming at linking the functions of environmental protection and health prevention.

\section{Declaration of interest}

The authors declare that they have no known competing financial interests or personal relationships that could have appeared to influence the work reported in this paper.

\section{Acknowledgements}

The authors acknowledge the financial support received from Assicurazioni Generali and Intesa San Paolo to realize the Environmental Virology laboratory run by Arpa Piemonte (Environmental Protection Agency of Piedmont) in La Loggia, Torino, Italy. The authors are grateful to the Molecular Virology Laboratory at Dept. of Clinical and Biological Science, Università degli Studi di Torino, for the technical support received.

The authors thank Società Metrpolitana Acque Torino S.p.a. for giving permission to use SARS-CoV-2 data obtained for Castiglione Torinese WWTP.

\section{References}

Ahmed, W., Angel, N., Edson, J., et al., 2020a. First confirmed detection of SARS-CoV-2 in untreated wastewater in Australia: A proof of concept for the wastewater surveillance of COVID-19 in the community. Science of the Total Environment (2020), https://doi.org/10.1016/j.scitotenv.2020.138764.

Ahmed, W., Bertsch, P., Bivins, A., Bibby, K., Farkas, K., Gathercole, A., et al., 2020b. Comparison of virus concentration methods for the RT-qPCR-based recovery of murine hepatitis virus, a surrogate for SARSCoV-2 from untreated wastewater. Science of the Total Environment 739 (2020) 139960.

Buonanno, G., Stabile, L., Morawska, L., 2020. Estimation of airborne viral emission: Quanta emission rate of SARS-CoV-2 for infection risk assessment. Environment International 141:105794.

D’Aoust, P.M., Mercier, É., Montpetit, D., Jia, J.J., Alexandrov, I., Tariq Baig, A., Mayne, J., Zhang, X., Alain, T., Servos, M.R., et al.2020. Quantitative analysis of SARS-CoV-2 RNA from wastewater solids in communities with low COVID-19 incidence and prevalence. medRxiv 2020, https://doi.org/10.1101/2020.08.11.20173062.

Furukawa N.W., Furukawa N.W., Brooks J.T., Sobel J.: Evidence supporting transmission of severe acute respiratory syndrome coronavirus 2 while presymptomatic or asymptomatic. Emerg Infect Dis 2020, 26:E1E6.

ISS, Istituto Superiore di Sanità, Rapporto 36/2020. Indicazioni sulle attività di balneazione in relazione alla diffusione del virus SARS-CoV-2. 
Kitajima, M., Ahmed, W., Bibby, K., Carducci, K., Gerba, C.P., Hamilton, K.A., Haramoto, E., Rose, J., 2020. SARS-CoV-2 in wastewater: State of the knowledge and research needs. Science of the Total Environment 739 (2020) 139076.

Marques, M., Domingo, J.L., 2021. Contamination of inert surfaces by SARS-CoV-2: Persistence, stability and infectivity. A review. Environmental Research 193 (2021) 110559.

Medema, G., Heijnen, L., Elsinga, G., Italiaander, R., Brouwer, A., 2020. Presence of SARS-Coronavirus-2 in sewage. medRxiv preprint 2020. https://doi.org/10.1101/2020.03.29.20045880.Morawska, L., Johnson, G.R., Ristovski, Z.D., Hargreaves, M., Mengersen, K., Corbett, S., Chao, C.Y.H., Li, Y., Katoshevski, D., 2009. Size distribution and sites of origin of droplets expelled from the human respiratory tract during expiratory activities. Journal of Aerosol Science 40, 256-269. https://doi.org/10.1016/j.jaerosci.2008.11.002

Ort, C., Lawrence, M.G., Reungoat, .J, Mueller, J.F.: Sampling for PPCPs in wastewater systems: comparison of different sampling modes and optimization strategies. Environ Sci Technol 2010, 44:6289-6296.

Regione Piemonte, 2020. Osservatorio Regionale dei Servizi Idrici Integrati. https://www.regione.piemonte.it/web/sites/default/files/media/documenti/2020-

08/00 Relazione SII 2019 rev giu-20.pdf

Tindale L.C., Stockdale J.E., Coombe M., Garlock E.S., Lau W.Y.V., Saraswat M., Zhang L., Chen D., Wallinga J., Colijn C.: Evidence for transmission of covid-19 prior to symptom onset. Elife 2020, 9:1-34.

Walsh, K.A., Jordan, K., Clyne, B., Rohde, D., Drummond, L., Byrne, P., Ahern, S., Carty, P.G., O’Brien, K.K., O'Murchu, E., et al. 2020. SARS-CoV-2 detection, viral load and infectivity over the course of an infection. J Infect 2020, 81:357-371.

Weidhaas, J., Aanderud, Z., Roper, D., VanDerslice, .J, Gaddis, E., Ostermiller, J., Hoffman, K., Jamal, R., Heck, P., Zhang, Y., et al. 2020. Correlation of SARS-CoV-2 RNA in wastewater with COVID-19 disease burden in sewersheds. https://doi.org/10.21203/rs.3.rs-40452/v1.

Wu, F., Xiao, A., Zhang, J., Gu, X., Lee, W.L., Kauffman, K., Hanage, W., Matus, M., Ghaeli, N., Endo, N., Duvallet, C., Moniz, K., Erickson, T., Chai, P., Thompson, J., Alm, E., 2020. SARS-CoV-2 titers in wastewater are higher than expected from clinically confirmed cases. medRxiv preprint https://doi.org/10.1101/2020.04.05.20051540

Wurtzer, S., Marechal, V., Mouchel, J.M., Maday, Y., Teyssou, R., Richard, E., Almayrac, J.L., Moulin, L.. 2020. Evaluation of lockdown impact on SARS-Co $1 \mathrm{~V}$-2 dynamics through viral genome quantification in Paris wastewaters. medRxiv preprint doi https://doi.org/10.1101/2020.04.12.20062679 


\section{Figure and Table legends}

Figure 1: Sewer network in Torino

Figure 2: Wastewater Treatment Plants considered in the study

Figure 3: Correlation between incidence of the disease (daily new COVID-19 cases, 7 days moving average) and SARS-CoV-2 concentration in wastewater (gene E) sampled at Castiglione Torinese treatment plant Figure 4: Correlation between incidence of the disease (daily new COVID-19 cases, 7 days moving average) and SARS-CoV-2 concentration in wastewater (gene E) sampled at Govone treatment plant Figure 5: Correlation between incidence of the disease (daily new COVID-19 cases, 7 days moving average) and SARS-CoV-2 concentration in wastewater (gene E) sampled at Asti treatment plant

Figure 6: Cycle Threshold values of the 3 different PCR targets (N1, N2 and E genes) obtained for wastewater collected by the treatment plant placed in Novara

Table 1: Wastewater Treatment Plants in Piedmont where samples were taken since September 2020 


\section{Figures}

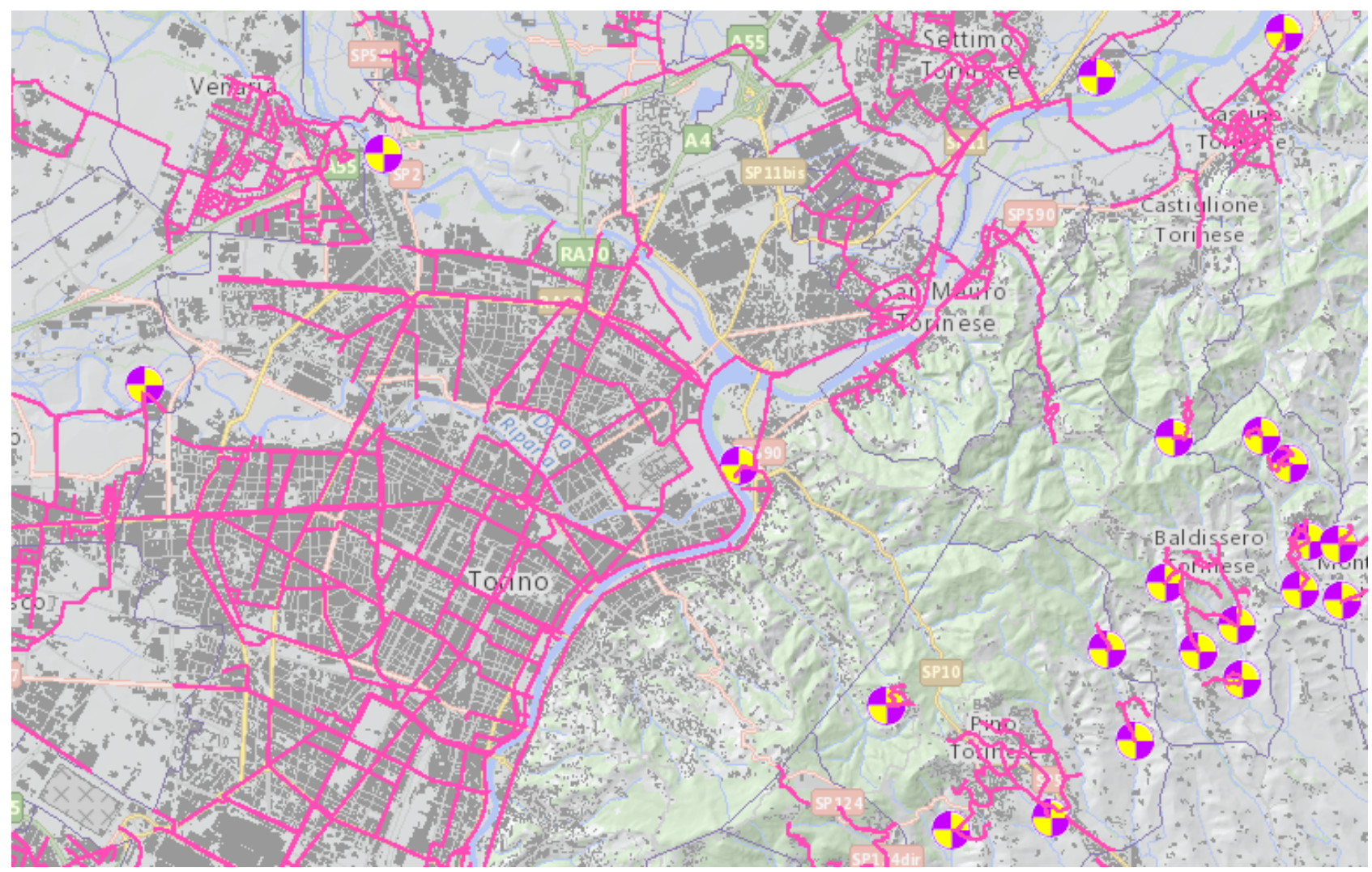

Figure 1: Sewer network in Torino 


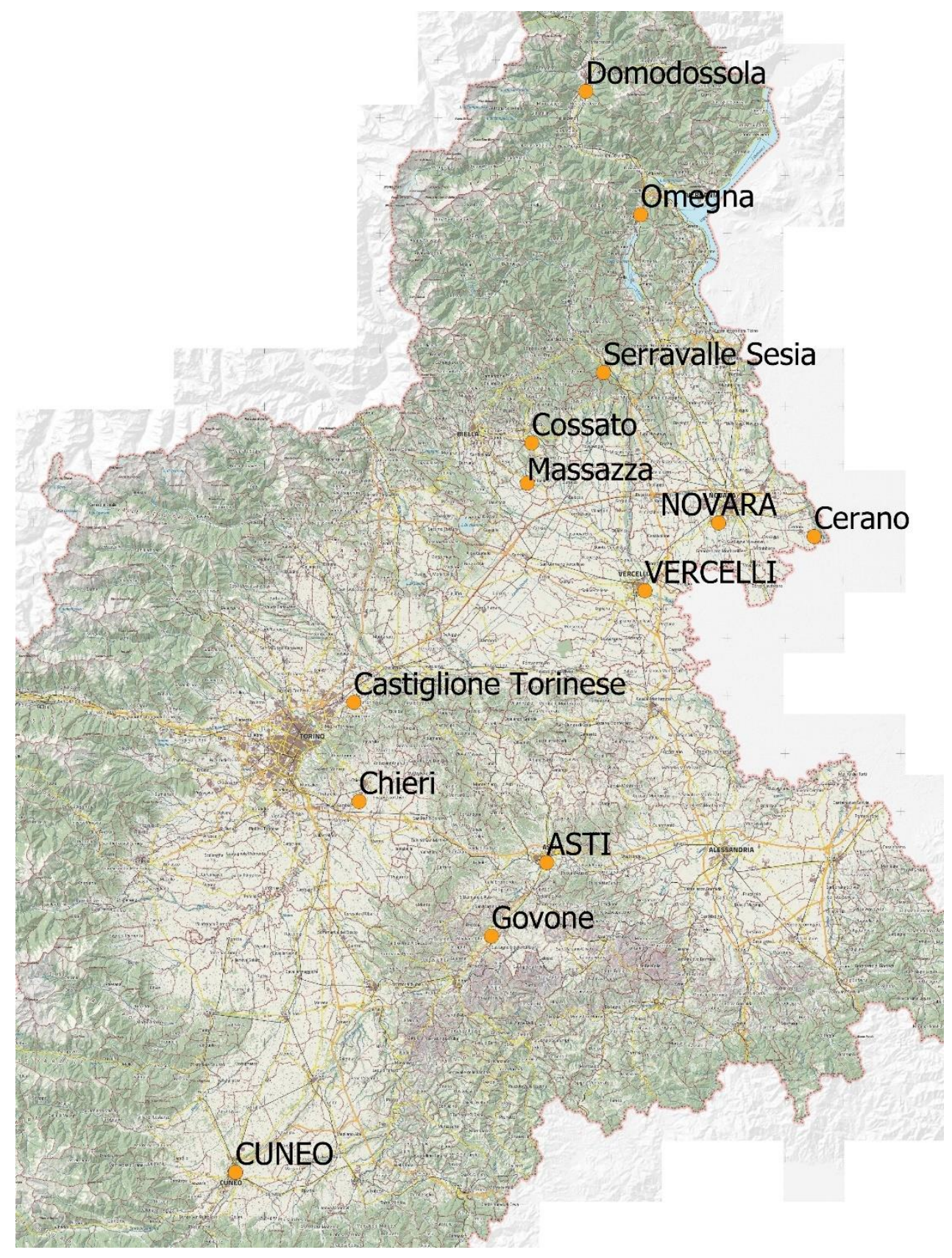

Figure 2: Wastewater Treatment Plants considered in the study 


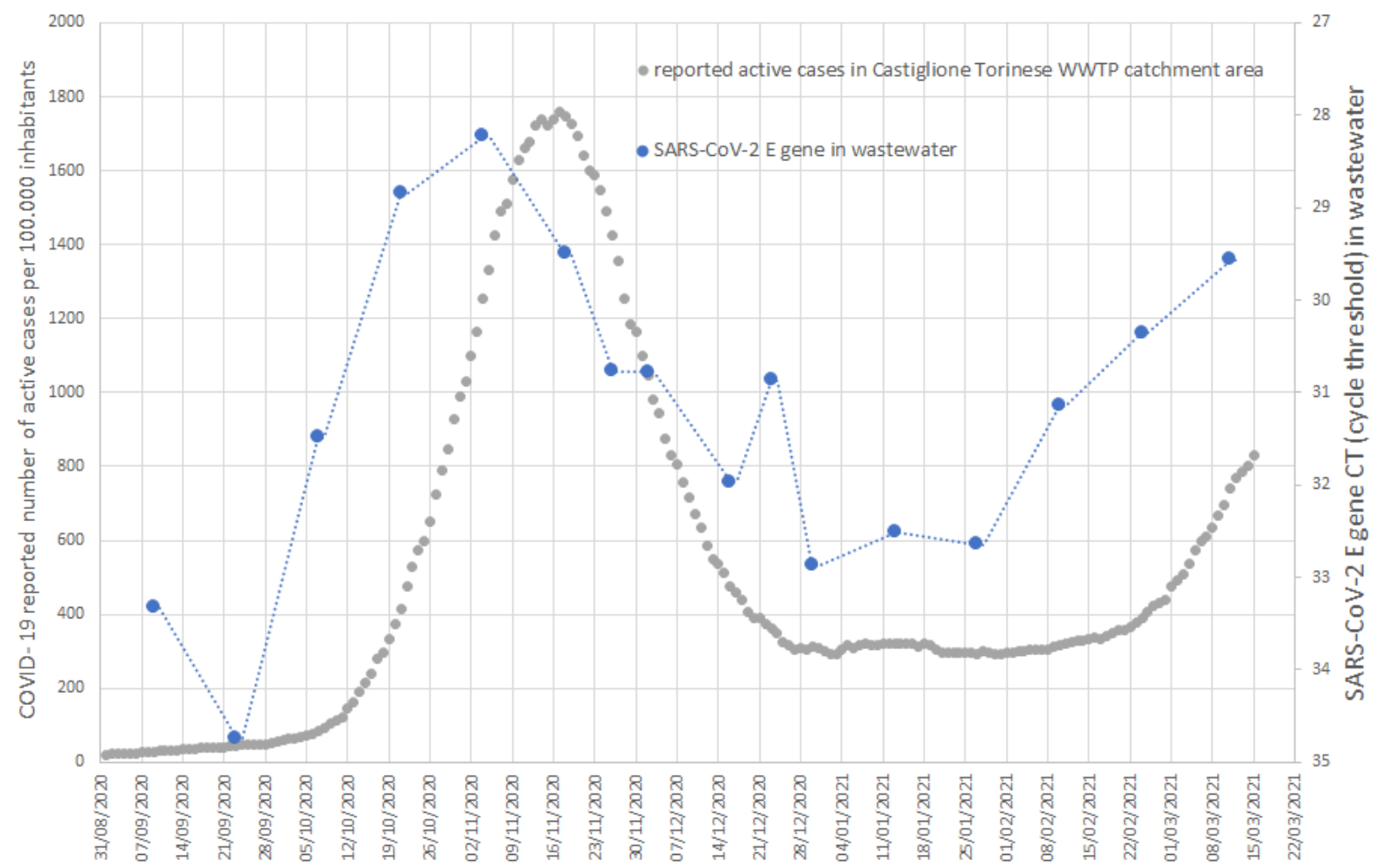

Figure 3: Correlation between prevalence of the disease and SARS-CoV-2 concentration in wastewater (gene E) sampled at Castiglione Torinese treatment plant $(1,449,080$ people served) 


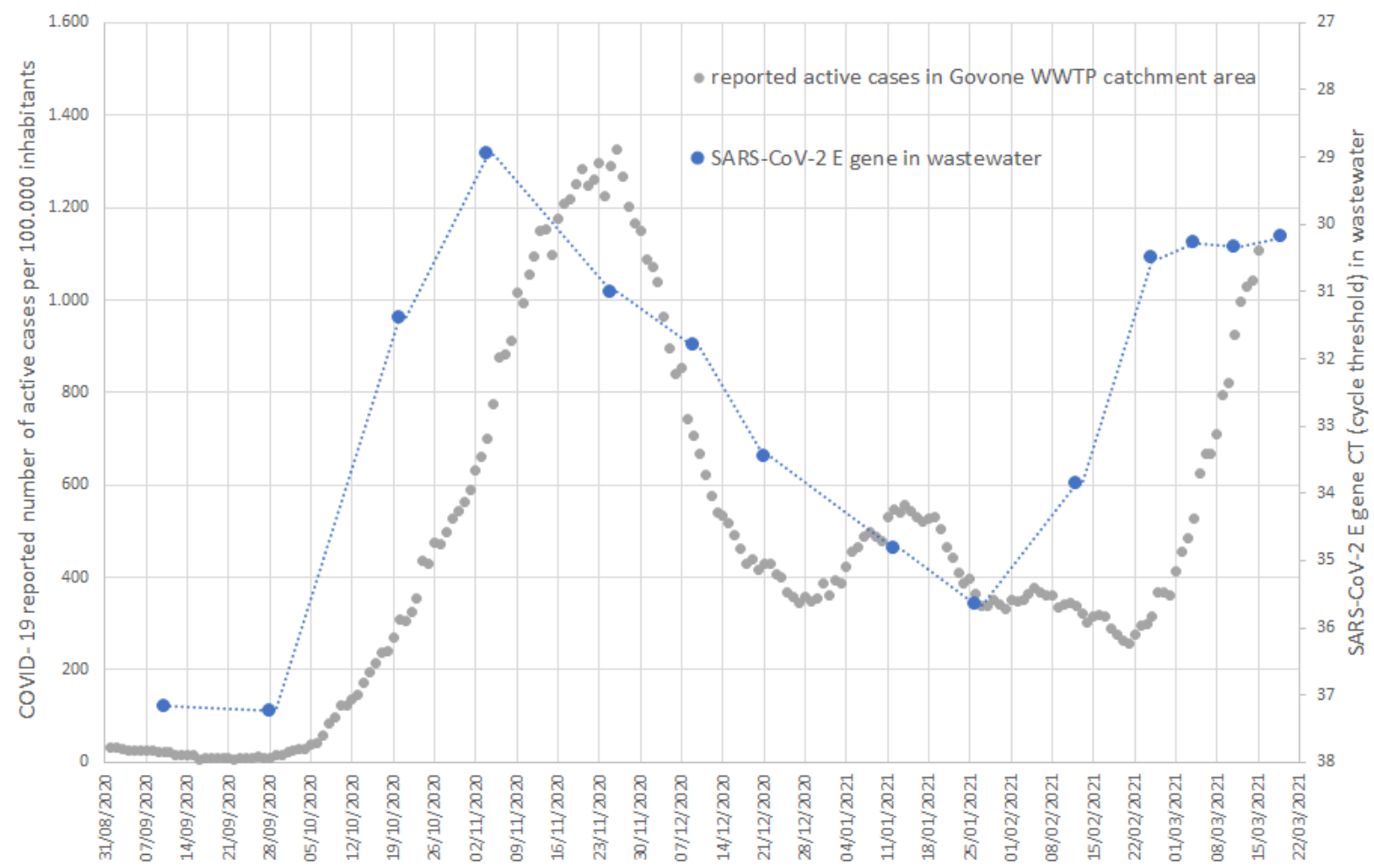

Figure 4: Correlation between prevalence of the disease and SARS-CoV-2 concentration in wastewater (gene E) sampled at Govone treatment plant (77,747 people served) 


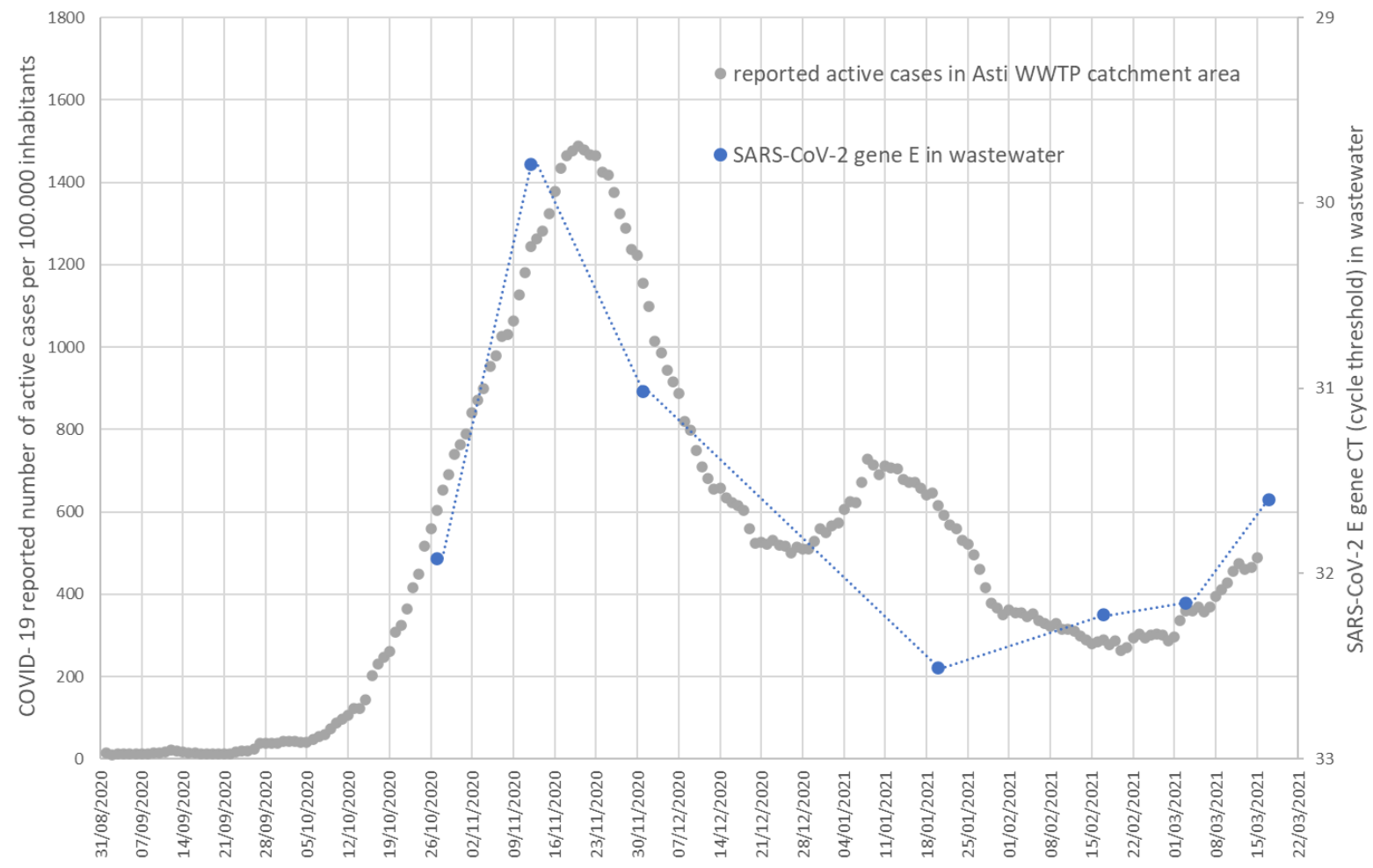

Figure 5: Correlation between prevalence of the disease and SARS-CoV-2 concentration in wastewater (gene E) sampled at Asti treatment plant ( 82,808 people served) 
28
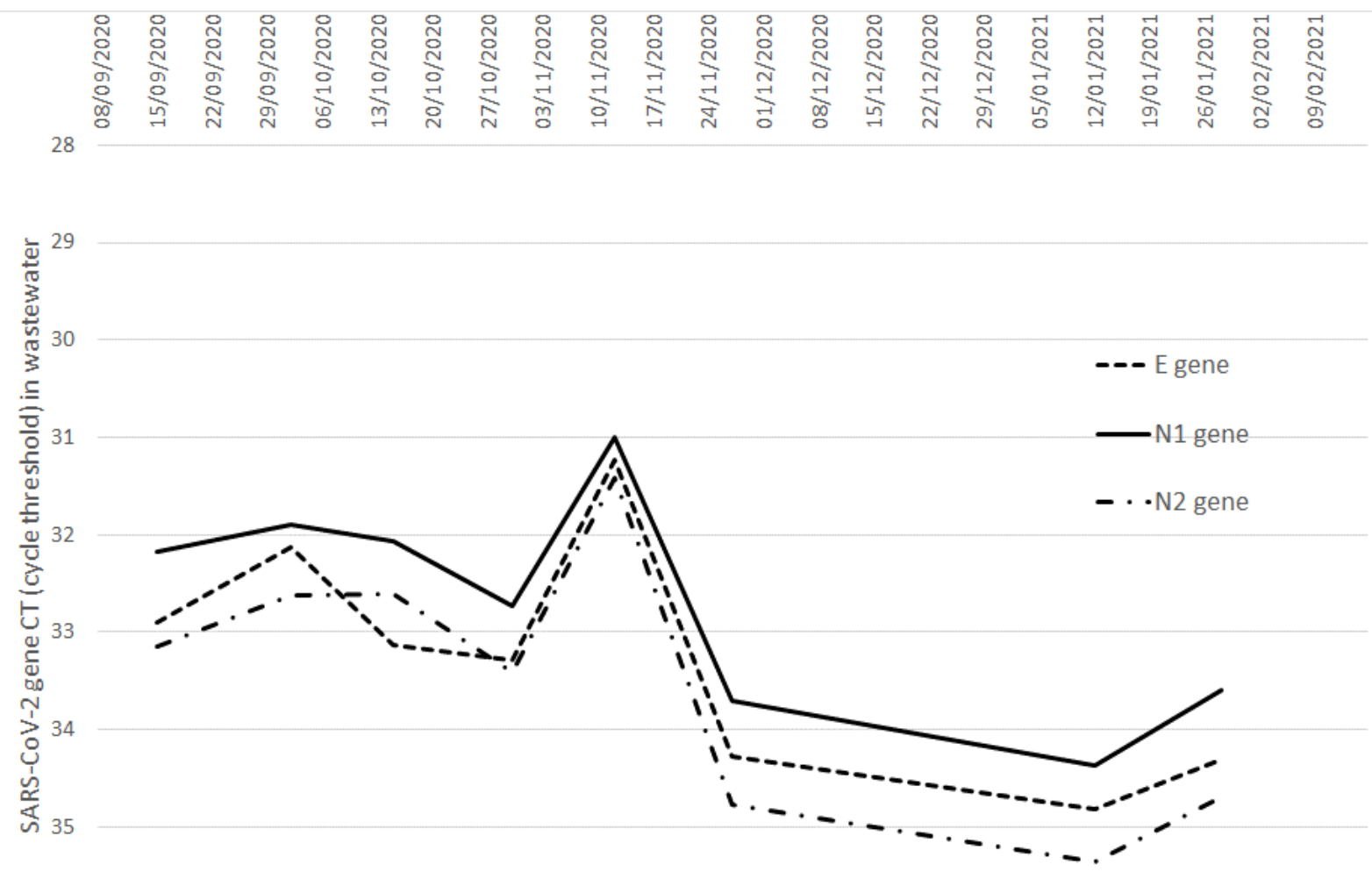

36

Figure 6: Cycle Threshold values of the 3 different PCR targets (N1, N2 and E genes) obtained for wastewater collected by the treatment plant placed in Novara 


\section{Tables}

Table 1: Wastewater Treatment Plants in Piedmont where samples were taken since September 2020

\begin{tabular}{|c|c|c|c|}
\hline TOWN & $\begin{array}{l}\text { PROVINCE } \\
\text { (inhabitants) }\end{array}$ & Population Equivalent (PE) & Project flow $\left(\mathrm{m}^{3} / \mathrm{d}\right)$ \\
\hline Castiglione Torinese & $\begin{array}{l}\text { Torino } \\
(2,230,946) \\
\end{array}$ & $3,839,940$ & 600,000 \\
\hline Chieri & $\begin{array}{l}\text { Torino } \\
(2,230,946)\end{array}$ & 60,000 & 20,581 \\
\hline Cuneo & $\begin{array}{l}\text { Cuneo } \\
(584,352)\end{array}$ & 185,000 & 37,000 \\
\hline Govone & $\begin{array}{l}\text { Cuneo } \\
(584,352)\end{array}$ & 240,000 & 60,000 \\
\hline Serravalle Sesia & $\begin{array}{l}\text { Vercelli } \\
(170,298)\end{array}$ & 84,000 & 28,800 \\
\hline Vercelli & $\begin{array}{l}\text { Vercelli } \\
(170,298)\end{array}$ & 80,000 & 18,000 \\
\hline Cerano & $\begin{array}{l}\text { Novara } \\
(369,018)\end{array}$ & 122,000 & 21,600 \\
\hline Novara & $\begin{array}{l}\text { Novara } \\
(369,018)\end{array}$ & 190,000 & 75,000 \\
\hline Asti & $\begin{array}{l}\text { Asti } \\
(214,342)\end{array}$ & 95,000 & 24,000 \\
\hline Domodossola & $\begin{array}{l}\text { Verbano-Cusio-Ossola } \\
(155,432)\end{array}$ & 32,000 & 8,640 \\
\hline Omegna & $\begin{array}{l}\text { Verbano-Cusio-Ossola } \\
(155,432)\end{array}$ & 29,000 & 7,250 \\
\hline Cossato & $\begin{array}{l}\text { Biella } \\
(174,384)\end{array}$ & 520,000 & 165,178 \\
\hline Massazza & $\begin{array}{l}\text { Biella } \\
(174,384)\end{array}$ & 37,000 & 25,722 \\
\hline
\end{tabular}

